\title{
Ionospheric tilting of 21 August 2017 total solar eclipse sounded by GNSS ground-based receivers and radio occultation
}

\author{
Chi-Yen Lin ${ }^{1,2}$, Jann-Yenq Liu ${ }^{1,2,3, *}$, Yang-Yi Sun ${ }^{4}$, Charles Chien-Hung Lin ${ }^{5}$, Loren C. Chang ${ }^{1,2}$, \\ Chao-Yen Chen ${ }^{6}$, and Chia-Hung Chen ${ }^{5}$ \\ ${ }^{1}$ Center for Astronautical Physics and Engineering, National Central University, Taoyuan City, Taiwan \\ ${ }^{2}$ Department of Space Science \& Engineering, National Central University, Taoyuan City, Taiwan \\ ${ }^{3}$ Center for Space and Remote Sensing Research, National Central University, Taoyuan City, Taiwan \\ ${ }^{4}$ Institute of Geophysics and Geomatics, China University of Geosciences, Wuhan, China \\ ${ }^{5}$ Department of Earth Science, National Cheng Kung University, Tainan City, Taiwan \\ ${ }^{6}$ National Space Organization, Hsinchu City, Taiwan
}

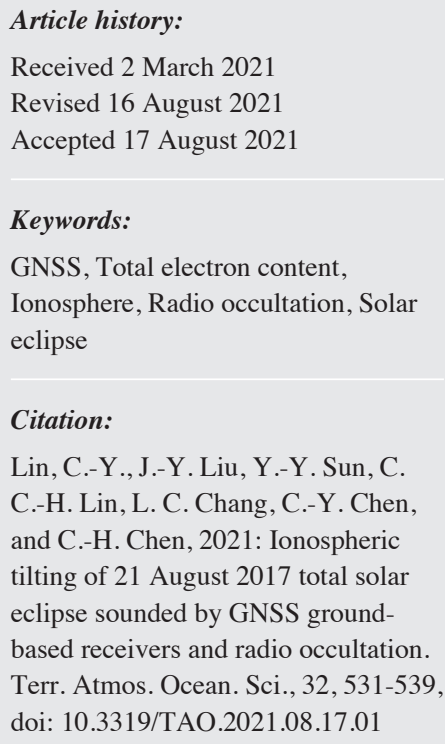

Received 2 March 2021

Revised 16 August 2021

Accepted 17 August 2021

Keywords:

GNSS, Total electron content, Ionosphere, Radio occultation, Solar eclipse

Citation:

Lin, C.-Y., J.-Y. Liu, Y.-Y. Sun, C. C.-H. Lin, L. C. Chang, C.-Y. Chen, and C.-H. Chen, 2021: Ionospheric tilting of 21 August 2017 total solar eclipse sounded by GNSS groundbased receivers and radio occultation. Terr. Atmos. Ocean. Sci., 32, 531-539, doi: 10.3319/TAO.2021.08.17.01

\begin{abstract}
A total solar eclipse passed over the continental United States from the west to the east coast on 21 August 2017. Measurements made by more than 2200 groundbased GNSS (Global Navigation Satellite System) receivers observed a significant decrease in ionospheric total electron content (TEC). Meanwhile, radio occultation soundings from the LEMUR2-LYNSEY-SYMO satellite record a double-peaked feature in the scanned TEC profile. A reproduction of the double-peaked feature on the TEC profile shows that the solar eclipse depresses the electron density and simultaneously tilts the ionosphere. This study, in turn, indicates the combination of the International Reference Ionosphere model and the GNSS TEC is a powerful tool for observing ionospheric space weather.
\end{abstract}

\section{INTRODUCTION}

The influences of a solar eclipse on the ionosphere using radar sounding have been studied extensively over the past decades. Evans (1965) use the incoherent backscatter method to observe the electron density, electron temperature, and ion temperature vertically during the eclipse of 20 July 1963. Cheng et al. (1992) study the ionospheric effect of a solar eclipse around the equatorial anomaly crest region using the ionospheric vertical sounding data, VLF propagation delay time data, and differential Doppler shift data. Tsai and Liu (1997) observe the atmospheric gravity waves induced by the solar eclipse using the digisonde virtual height profiles. Liu et al. (1998) examine the digisonde vertical

\footnotetext{
* Corresponding author

E-mail:jyliu@jupiter.ss.ncu.edu.tw
}

phase and group propagation of gravity waves in the ionosphere during a solar eclipse. Besides, ground-based GPS observation can provide horizontal ionospheric variation induced by the solar eclipse. Liu et al. (1999) utilize GPS vertical total electron content (TEC) measurements to study the ionospheric variations during a solar eclipse. Tsai and Liu (1999) demonstrate that the GPS TEC network enables examining the ionospheric response to the eclipse over a large area. Liu et al. (2011) present that ionospheric TEC records bow and stern waves triggered by the moon's shadow. Lin et al. (2012) apply assimilation analysis results, which use ground-based GPS TEC, to reveal the solar eclipse's influence on the ionosphere.

A total solar eclipse passed over the continental United States (CONUS) from the west to the east coast on 21 August 2017. The International GNSS Service (IGS) and 
Continuously Operating Reference Station (CORS) provide measurements from more than 2200 ground-based GNSS receivers in the United States. These massive TEC observations serve to monitor ionospheric changes over a broader area $\left(25-55^{\circ} \mathrm{N}, 75-125^{\circ} \mathrm{W}\right)$. During the eclipse, numerous dramatic signatures are reported. Coster et al. (2017) analyze the TEC data and evidence the presence of enhanced large-scale traveling ionospheric disturbances (TIDs) during eclipse passage. Zhang et al. (2017) detect strong signatures of ionospheric bow waves in the central and eastern United States. Sun et al. (2018) demonstrate that the moon shadow-induced acoustic shock wave results in the bow wave trough and crest near the totality path. Reinisch et al. (2018) use digisonde measurements to observe the ionosphere electron density for the 21 August 2017 solar eclipse at the Idaho National Laboratory. The result shows that foE and foF1 vanish rapidly during the obscuration period. Moreover, a growth of plasma irregularities on the bottom side ionosphere was observed by an ionosonde (Pradipta et al. 2018), while topside ionospheric disturbances were observed by GNSS radio occultation (RO) observations (Perry et al. 2019) during the eclipse.

Nowadays, the RO technique is very common to scan the ionospheric vertical distribution, such as satellite mission FORMOSAT-3/COSMIC (F3/C) can provide about 2500 globally distributed occultations daily (Schreiner et al. 2007). With a large amount of RO observations, the three-dimensional description of the ionospheric density structure, for example, the Weddell Sea Anomaly (Lin et al. 2009) and monthly variations of the mid-latitude summer nighttime anomaly (Lin et al. 2010), can be studied. Moreover, Sun et al. (2016) present that the seismic waves can be impacted on ionospheric electron density $(\mathrm{Ne})$ structures near the altitude of peak $\mathrm{Ne}(\mathrm{hmF} 2)$ in the vertical direction by using RO observation. In addition, Liu et al. (2010, 2015) discuss the influences of Abel inversion assumption as well as different LEO satellite altitudes to the RO electron density profile in detail. Those previous studies show that RO observation, in turn, provides an excellent chance to study the ionosphere in the vertical direction, especially during the solar eclipse. In this study, a reconstruction is produced to mimic the solar eclipse tilting of the ionosphere revealed by the RO observations.

\section{RO OBSERVATION}

A satellite named LEMUR2-LYNSEY-SYMO (L2LS), operated by Spire Global, Inc., scans the vertical ionosphere structure using the RO technique. Figure 1a illustrates the sounding geometry (white lines) and tangent points (red line) of the LEO satellite scans of the ionosphere on the map during the solar eclipse period on 21 August 2017. The significant TEC depletion region is within the $60 \%$ obscuration region (black dash contour denotes the obscuration distribution). The orientation (black arrow) of satellite L2LS is southward during the solar eclipse. The geometry of RO sounding indicates that the observation contains ionospheric information corresponding to both vertical and horizontal distribution. The observed RO TEC profile (Fig. 1b) sounded around the eclipse shadow area shows a double-peaked feature that is an additional peak (Peak-2) above the major peak (Peak-1). The sounding paths of Peak1 (gray dash line) and Peak-2 (solid gray line) are around the edge of significant TEC depletion, and the Peak-1 is at a tangent-point height of $167.11 \mathrm{~km}$ and Peak-2 is at that of $249.15 \mathrm{~km}$. The RO TEC used in this study is calibrated by the TEC of the auxiliary side. Since the ionosphere is not the spherical symmetry during the solar eclipse, the Abel inversion might induce huge errors in the electron density profile. In this study, only RO TEC profiles are implemented to avoid the error of Abel inversion. Moreover, Høeg et al. (1998) report that the error value of slant path TEC is $\sim 3$ TECu for high TEC value (daytime, solar maximum) and $\sim 1$ TECu for median TEC value. In this study, the RO sounding is under the solar eclipse. The maximum value of slant path TEC is less than $70 \mathrm{TECu}$. Therefore, the error of slant path TEC shall about 1 TECu and might not influence a lot.

The electron density in the lower part of the ionosphere vanishes rapidly during the obscuration period (e.g., Reinisch et al. 2018), resulting in the artificial uplift of hmF2, tilts the ionospheres, and causes the double-peaked feature on the RO TEC profile. To see whether the double-peaked case in RO TEC profiles being common, 10 RO TEC profiles over the CONUS around the similar eclipse period between 16:00 and 20:00 UTC 7 days before and after the solar eclipse day (DOY 226-240) sounded by F3/C are examined. Figure 2 illustrates that no obvious additional peak above the major peak can be found on the 10 TEC profiles on those reference days, which suggests that during the solar eclipse, the tilted ionosphere causes the double-peaked feature.

\section{METHOD AND EXPERIMENTS}

To provide evidence that the double-peak feature of the RO TEC profile is due to the ionospheric tilting, we reproduce the RO TEC profile by integrating reconstructed three-dimensional (3D) electron density distribution computed by International Reference Ionosphere (IRI) 2016 (Bilitza et al. 2017) along the RO sounding paths of L2LS. When the reproduced RO TEC profile and observation yield a good agreement, the reconstructed electron density distribution might close to reality. We implement three steps to reconstruct the TEC profile. First, giving F2-peak heights (hmF2), we apply IRI-2016 to construct the 3D electron density with the grid resolution of $1^{\circ}$ latitude, $1^{\circ}$ longitude, and $5 \mathrm{~km}$ altitude, and calculate vertical IRI TEC maps with grid resolution of $1^{\circ}$ latitude and $1^{\circ}$ longitude. On the other hand, measurements of more than 2200 ground-based 


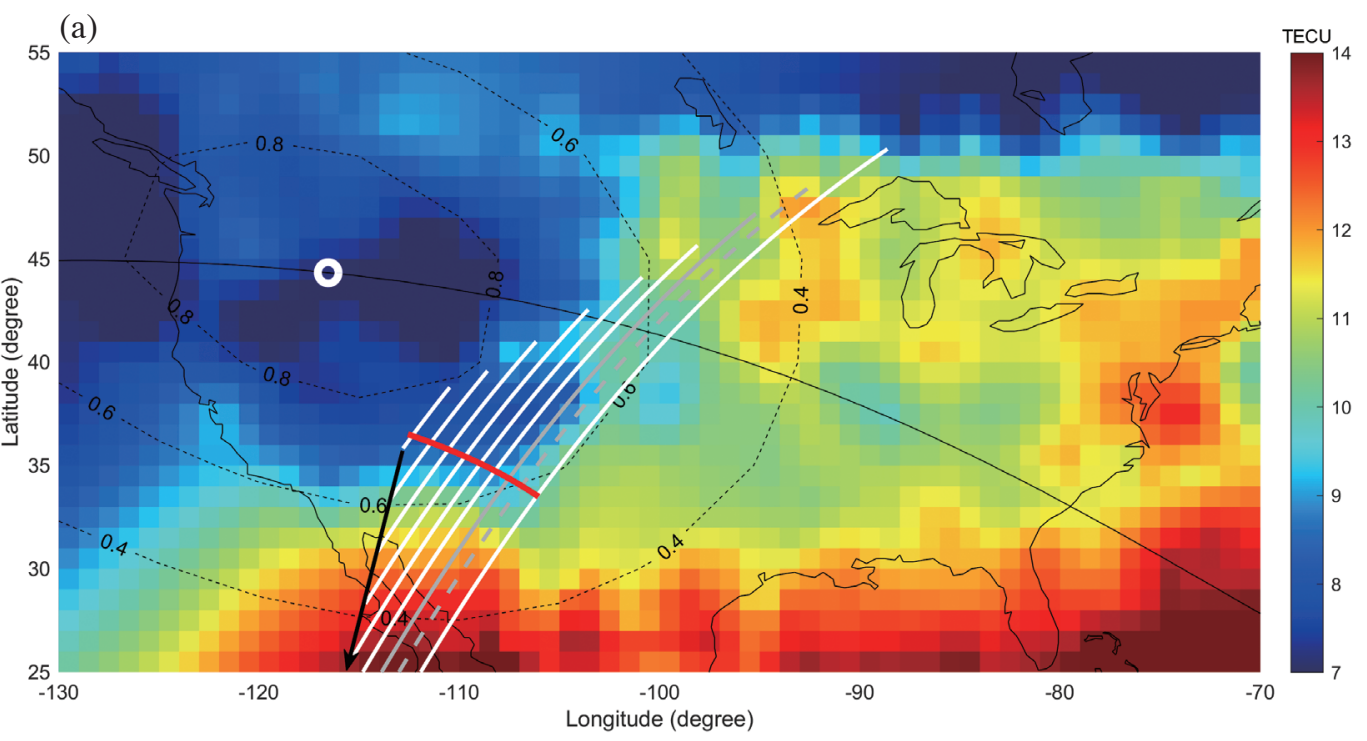

(b)

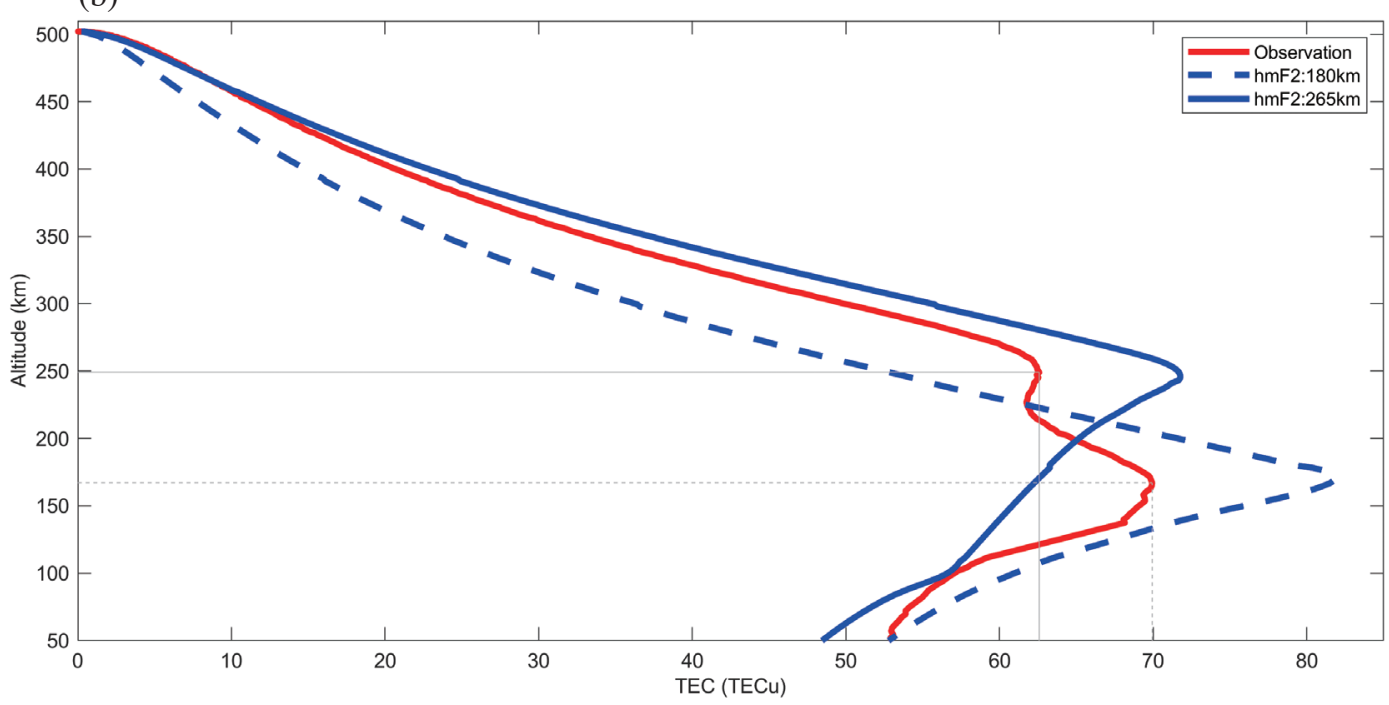

Fig. 1. Ionospheric electron density depletion due to the eclipse scanned by the radio occultation technique. (a) Gridded GNSS TEC distribution at 17:27 UTC by using IGS and CORS observation data together with TGIM (Sun et al. 2017) filling up the dataless of TEC map. The white lines denote radio occultation (RO) sounding geometry, which is near perpendicular to the tilt TEC gradient. The dash (solid) gray line represents the sounding ray path of Peak-1 (Peak-2). The red line is the tangent points of RO sounding. The white circle denotes the totality location. The dash black contour indicates the obscuration and the solid black path displays the totality trace. The black arrow denotes the orientation of LEO satellite L2LS. (b) The red line represents the observed TEC profile, which has an additional peak (Peak-2) above the major peak (Peak-1). The dash blue line (solid blue line) shows the reproduced TEC profiles integrated from reconstructed 3D electron density with a synthetic constant $180 \mathrm{~km}(265$ $\mathrm{km}) \mathrm{hmF} 2$ distribution. 

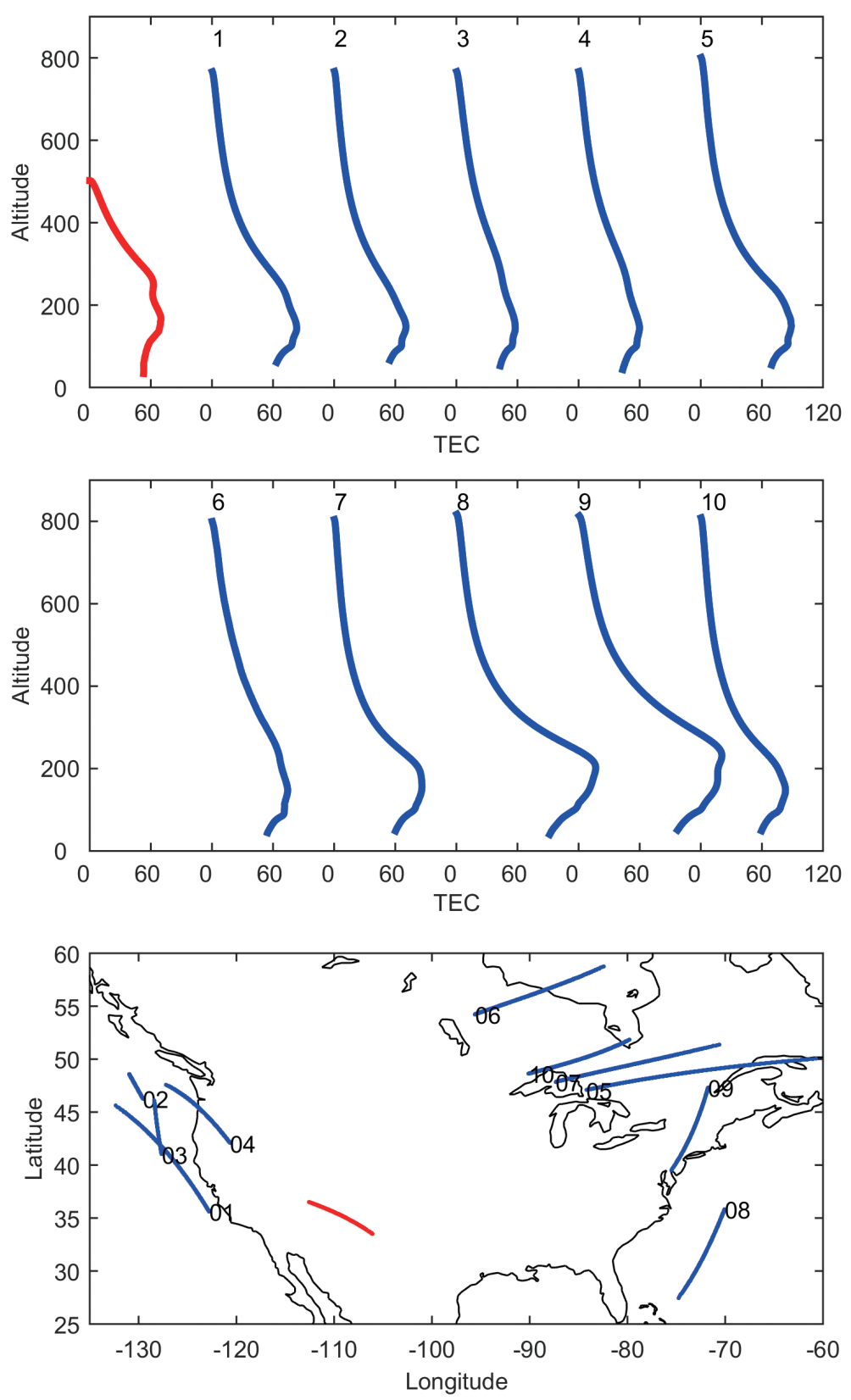

Fig. 2. Radio occultation TEC (total electron content) profile (red) observed by satellite operated by Spire Global, Inc. during solar eclipse on 21 August 2017 and TEC profiles (blue) over the continental United States during the similar UTC time period between 16:00 and 20:00 UTC 7 days before and after the solar eclipse (DOY 226-240) observed by FORMOSAT-3/COSMIC and their sounding tangent point locations. 
GNSS receiving stations from IGS and CORS in the CONUS, are used to develop GNSS TEC maps with grid resolution of $1^{\circ}$ latitude and $1^{\circ}$ longitude. The TEC value at each grid is the median of all data within the grid, while grids of data gaps are filled by the TEC of TGIM (Sun et al. 2017). Next, to find the horizontal information, we calculate the ratio of GNSS TEC to IRI TEC for each grid. Over each grid, the electron density multiplies the associated ratio to derive the 3D electron density with the GNSS TEC horizontal information. Finally, the RO TEC profile is obtained by integrating the 3D electron density along the L2LS sounding paths. It is noteworthy that the reconstructed RO TEC profile contains given vertical and horizontal information.

The first experiment is to investigate the influence of the $\mathrm{hmF} 2$ value on the reproduced RO TEC profile. The reconstructed electron density is with a synthetic constant $\mathrm{hmF} 2$ distribution and horizontal GNSS TEC map. Figure $1 \mathrm{~b}$ represents the reproduced TEC profiles from the given synthetic constant hmF2 located at $265 \mathrm{~km}$ (solid blue curve) and $180 \mathrm{~km}$ (blue dash curve), respectively. The results show that both the TEC profiles yield a single peak, and the peak heights are similar to Peak-1 and Peak-2. This suggests that a horizontal plane stratified ionosphere with a single $\mathrm{hmF} 2$ can result in one peak on the RO TEC profile. A crosscomparison of the two profiles shows that the peak height of the RO TEC profile is a function of $\mathrm{hmF} 2$. This experiment indicates that the moon shadow can tilt the ionosphere and results in a sudden change of $\mathrm{hmF} 2$. To examine the hypothesis of the tilted ionosphere resulting in the double-peaked RO TEC profile, we conduct the construction of the ionosphere with a synthetic hmF2 tilting (Fig. 3a). The synthetic tilt gives a sudden $\mathrm{hmF} 2$ change from $205 \mathrm{~km}$ altitude in the low obscuration side to $265 \mathrm{~km}$ altitude in the high one, which results in a sudden tilt of the ionosphere between the sounding ray paths of Peak-1 and Peak-2. The reconstructed $3 \mathrm{D}$ electron density with the synthetic tilt hmF2 is examined by assuming the ground-based TEC to be constant in the horizontal direction. The assumed constant TEC value is $6 \mathrm{TECu}$, which is vertically integrated the electron density from 0 to $800 \mathrm{~km}$, in both tilt and un-tilt regions. Figure $3 \mathrm{c}$ displays that the reproduced TEC profile (blue dash curve) contains Peak-2 appearing above Peak-1. The reproduce Peak-2 well agree with the observation; however, the reproduced Peak-1 is underestimated.

To mimic the ionospheric solar eclipse effect, both the tilted ionosphere and the horizontal distribution of the observed ground-based GNSS TEC have to be taken into account. Figure $3 \mathrm{~b}$ displays the $3 \mathrm{D}$ sounding geometry and the reconstructed ionosphere indicates that sounding paths observe the edge of tilt. Figure $3 \mathrm{c}$ reveals the reproduced TEC profile (solid blue curve), the peak heights and TEC values of Peak-1 and Peak-2 have a good agreement with the observation. Finally, to elucidate the importance of sounding geometry to the double-peaked TEC profile feature, this study performs an experiment using a sounding path with a different direction. All the other criteria are retained. The original sounding path is near perpendicular to the TEC gradient. Figure 4 illustrates the geometry of the rotated sounding path and its reproduced TEC profile. The rotated sounding path is near parallel to the TEC gradient, resulting in sounding paths contain both tilt and un-tilt information in the vertical and horizontal distribution. The reproduced TEC profile has only one peak if the sounding geometry is near parallel to the TEC gradient.

\section{DISCUSSION AND CONCLUSION}

The L2LS satellite recorded a double-peaked feature during the 21 August 2017 solar eclipse. In this study, we have performed the reconstruction experiment to find the cause. The constant $\mathrm{hmF} 2$ experiment shows that a solo electron density depletion due to the solar eclipse cannot generate the double-peaked feature, while the tilt hmF2 experiment indicates that the tilted ionosphere results in the double-peaked feature, but the reproduced TEC values are underestimated. By contrast, the reproduced RO TEC profile agrees well with the observations if both the synthetic tilted ionosphere and observed GNSS TEC horizontal distribution are taken into account. In fact, besides the above two criteria of the tilted ionosphere and horizontal TEC gradient, the relative position between the RO sounding ray path and tilt gradient is also essential. If the sounding path is rotated by about 90 degrees (the other criteria are fixed), the reproduced RO TEC profile will not find the doublepeaked feature. Thus, these studies provide evidence that RO sounding is a powerful technique to observe the transit plasma structures in the ionosphere. In conclusion, the observation of the RO TEC profile is well reproduced by the simulation, which confirms that the double-peak feature requires the ionospheric tilting and the electron density depletion together with a RO sounding particular to the TEC horizontal gradient. This coincident RO sounding indicates that the moon shadow from a solar eclipse can significantly tilt the ionosphere.

Acknowledgements TEC data was kindly provided by Spire Global, Inc. via one of the company's 3U CubeSats. For more information about Spire, visit spire.com (https:// spire.com/). The authors gratefully acknowledge the International GNSS Service (IGS) (http://garner.ucsd.edu/) and Continuously Operating Reference Station (CORS) (https://geodesy.noaa.gov/CORS/data.shtml) for providing the ground-based GNSS data, and COSMIC Data Analysis and Archive Center (CDAAC) and Taiwan Analysis Center for COSMIC (TACC) for providing FORMOSAT-3/COSMIC data (http://cdaac-www.cosmic ucar.edu/, https://tacc. cwb.gov.tw/). We wish to thank the International Reference Ionosphere (IRI) working group for providing the Fortran 
(a)

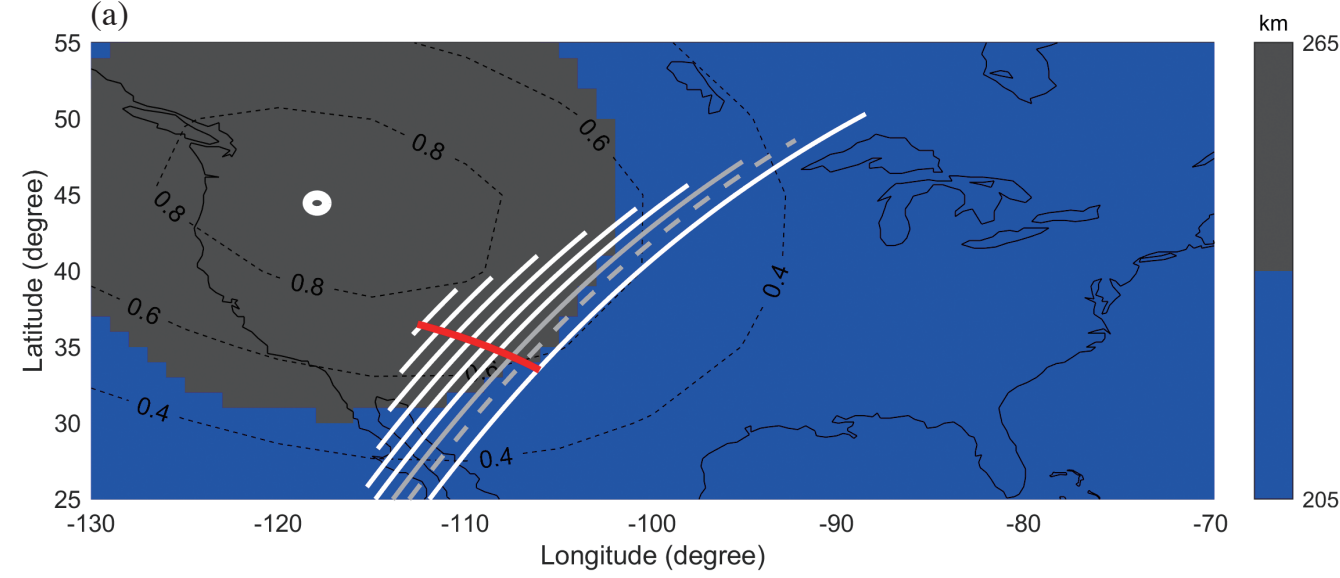

(b)

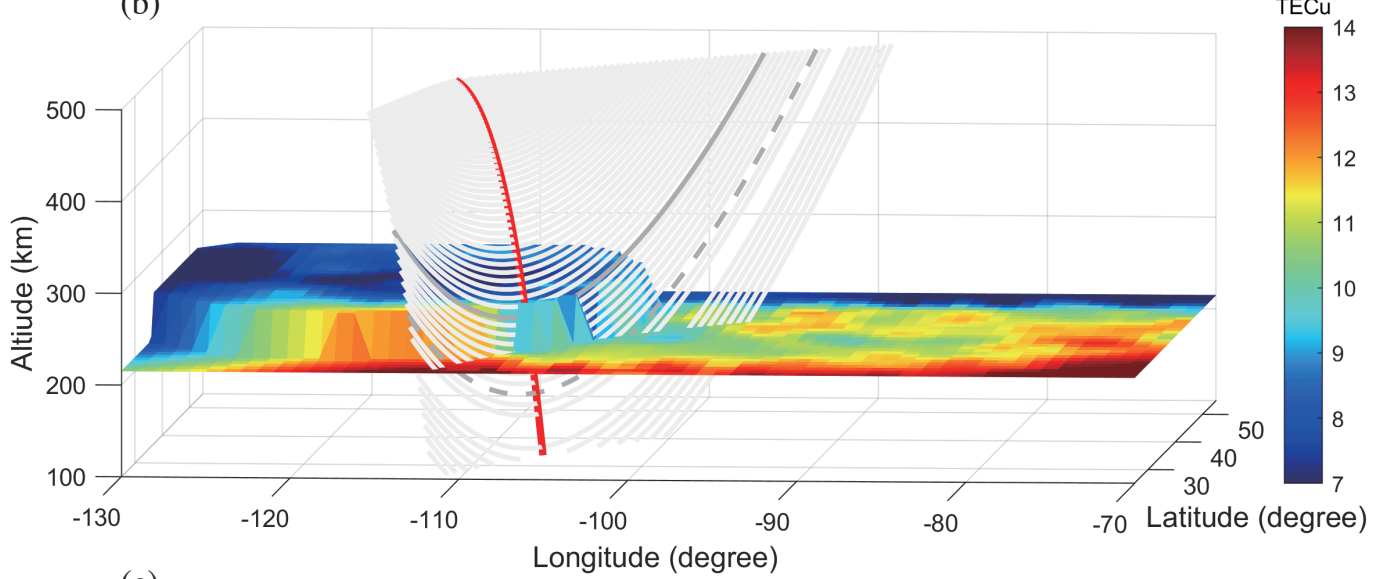

(c)

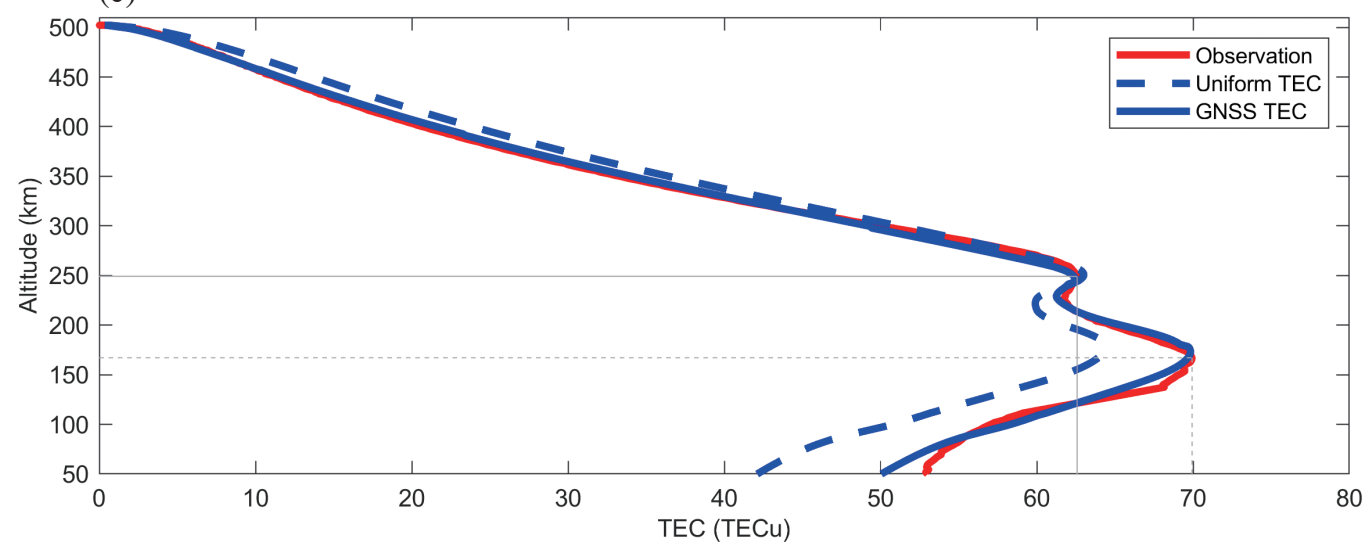

Fig. 3. Reproduction of the RO TEC profile using the synthetic tilt hmF2 during the eclipse. (a) Synthetic tilt hmF2 distribution and radio occultation sounding geometry. (b) The geometry of RO sounding and tilted ionosphere in three dimensions. The surface represents the hmF2 distribution and contour displays gridded GNSS TEC distribution at 17:27 UTC. (c) Reproduced TEC profiles integrated from reconstructed electron density with synthetic tilt hmF2 distribution and constant horizontal distribution (dash blue line) or gridded GNSS TEC horizontal distribution (solid blue line). 


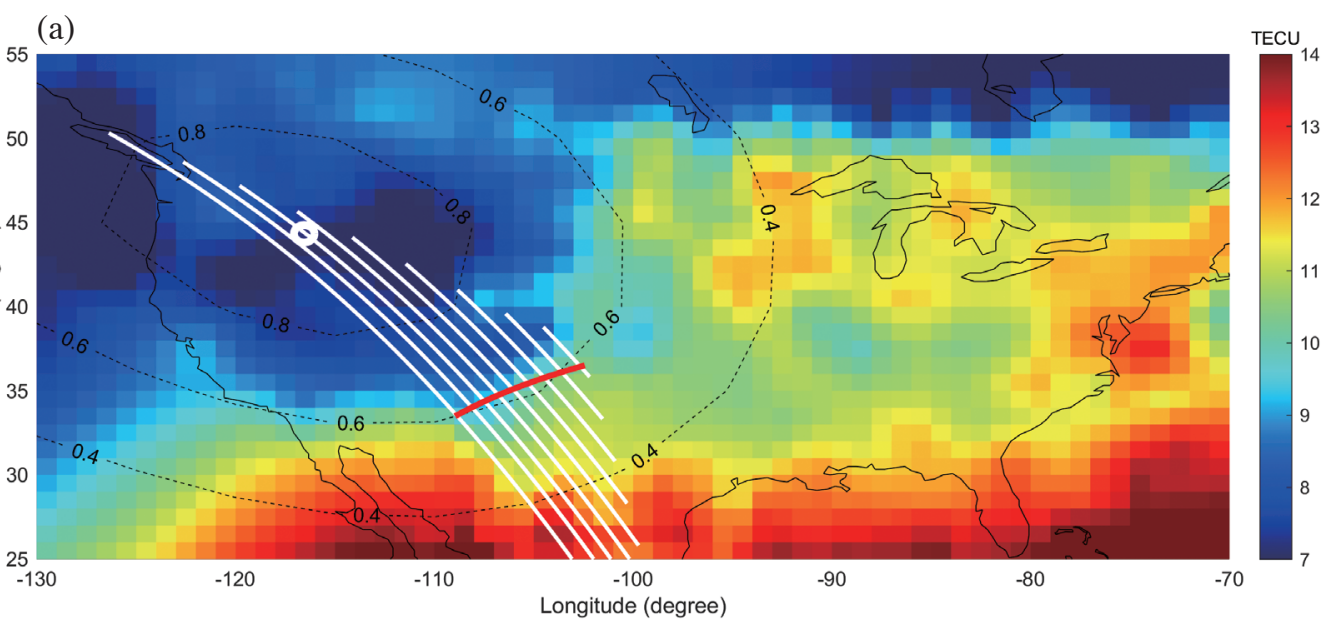

(b)

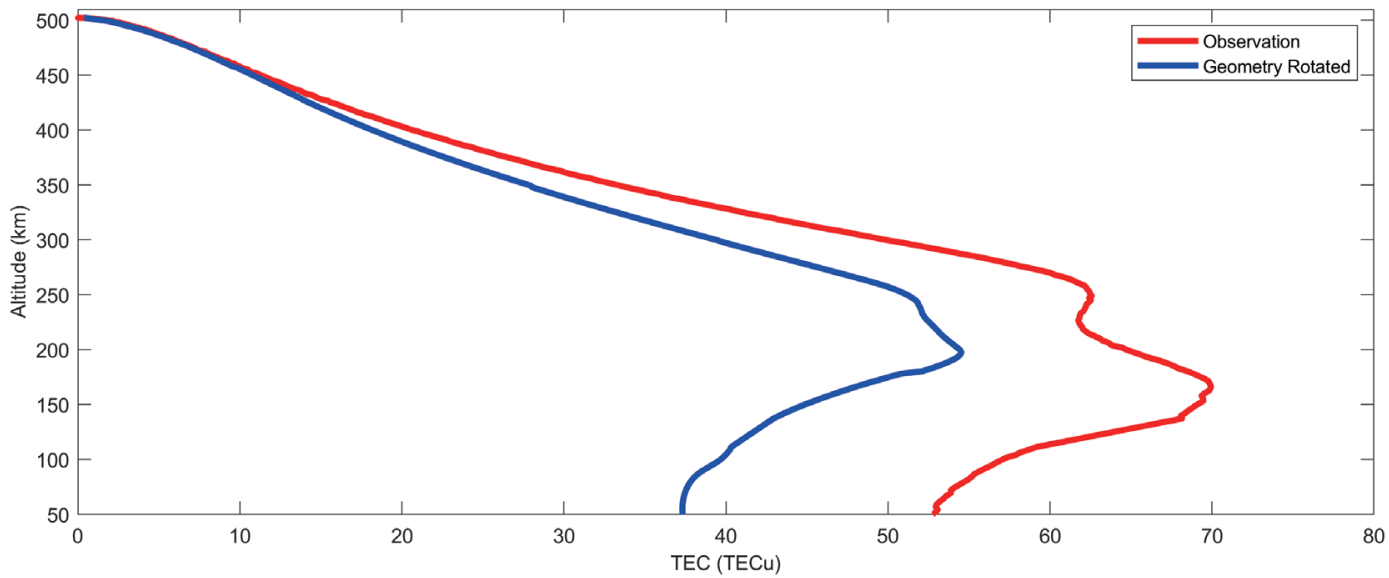

Fig. 4. Reproduction of a RO TEC profile with the sounding geometry (white lines) is near parallel to the tilt TEC gradient. (a) Gridded GNSS TEC map at 17:27 UTC and rotated radio occultation sounding geometry. The red line illustrates the tangent points of RO sounding. (b) Observed TEC profile (red line) and reproduced TEC profiles integrated from reconstructed electron density with synthetic tilt hmF2 and gridded GNSS TEC horizontal distribution (blue line). 
source code of IRI-2016 (http://irimodel.org/IRI-2016/). This study is supported by the Taiwan Ministry of Science and Technology grant MOST 108-2111-M-008-045MY2 and 109-2111-M-008-008. This study is supported by the ISSI-Bern International Team of "Ionospheric Space Weather Studied by RO and Ground-based GNSS TEC Observations" [the team leader J.-Y. Liu (TW)]. This work was financially supported by the Center for Astronautical Physics and Engineering (CAPE) from the Featured Area Research Center program within the framework of Higher Education Sprout Project by the Ministry of Education (MOE) in Taiwan.

\section{REFERENCES}

Bilitza, D., D. Altadill, V. Truhlik, V. Shubin, I. Galkin, B. Reinisch, and X. Huang, 2017: International reference ionosphere 2016: From ionospheric climate to realtime weather predictions. Space Weather, 15, 418-429, doi: 10.1002/2016SW001593. [Link]

Cheng, K., Y.-N. Huang, and S.-W. Chen, 1992: Ionospheric effects of the solar eclipse of September 23, 1987 , around the equatorial anomaly crest region. $J$. Geophys. Res., 97, 103-111, doi: 10.1029/91JA02409. [Link]

Coster, A. J., L. Goncharenko, S.-R. Zhang, P. J. Erickson, W. Rideout, and J. Vierinen, 2017: GNSS observations of ionospheric variations during the 21 August 2017 solar eclipse. Geophys. Res. Lett., 44, 12041-12048, doi: 10.1002/2017GL075774. [Link]

Evans, J. V., 1965: An $F$ region eclipse. J. Geophys. Res., 70, 131-142, doi: 10.1029/JZ070i001 p00131. [Link]

Høeg, P., G. B. Larsen, H.-H. Benzon, J. Grove-Rasmussen, S. Syndergaard, M. D. Mortensen, J. Christensen, and K. Schultz, 1998: GPS Atmosphere Profiling Methods and Error Assessments, Scientific Report 98-7, Danish Meteorological Institute, Copenhagen, Denmark, 203 pp.

Lin, C. H., J. Y. Liu, C. Z. Cheng, C. H. Chen, C. H. Liu, W. Wang, A. G. Burns, and J. Lei, 2009: Three-dimensional ionospheric electron density structure of the Weddell Sea anomaly. J. Geophys. Res., 114, A02312, doi: 10.1029/2008JA013455. [Link]

Lin, C. H., C. H. Liu, J. Y. Liu, C. H. Chen, A. G. Burns, and W. Wang, 2010: Midlatitude summer nighttime anomaly of the ionospheric electron density observed by FORMOSAT-3/COSMIC. J. Geophys. Res., 115, A03308, doi: 10.1029/2009JA014084. [Link]

Lin, C.-Y., J.-Y. Liu, C.-H. Lin, Y.-Y. Sun, E. A. AraujoPradere, and Y. Kakinami, 2012: Using the IRI, the MAGIC model, and the co-located ground-based GPS receivers to study ionospheric solar eclipse and storm signatures on July 22, 2009. Earth Planets Space, 64, 513-520, doi: 10.5047/eps.2011.08.016. [Link]
Liu, J. Y., C. C. Hsiao, L. C. Tsai, C. H. Liu, F. S. Kuo, H. Y. Lue, and C. M. Huang, 1998: Vertical phase and group velocities of internalgravity waves derived from ionograms during the solareclipse of 24 October 1995. J. Atmos. Sol.-Terr. Phys., 60, 1679-1686, doi: 10.1016/s1364-6826(98)00103-5. [Link]

Liu, J. Y., H. F. Tsai, L.-C. Tsai, and M. Q. Chen, 1999: Ionospheric total electron content observed during the 24 October 1995 solar eclipse. Adv. Space Res., 24, 14951498, doi: 10.1016/s0273-1177(99)00713-9. [Link]

Liu, J. Y., C. Y. Lin, C. H. Lin, H. F. Tsai, S. C. Solomon, Y. Y. Sun, I. T. Lee, W. S. Schreiner, and Y. H. Kuo, 2010: Artificial plasma cave in the low-latitude ionosphere results from the radio occultation inversion of the FORMOSAT-3/COSMIC. J. Geophys. Res., 115, A07319, doi: 10.1029/2009JA015079. [Link]

Liu, J. Y., Y. Y. Sun, Y. Kakinami, C. H. Chen, C. H. Lin, and H. F. Tsai, 2011: Bow and Stern Waves Triggered by the Moon's Shadow Boat. Geophys. Res. Lett., 38, L17109, doi: 10.1029/2011GL048805. [Link]

Liu, J. Y., C. Y. Lin, and H. F. Tsai, 2015: Electron density profiles probed by radio occultation of FORMOSAT-7/COSMIC-2 at 520 and $800 \mathrm{~km}$ altitude. Atmos. Meas. Tech., 8, 3069-3074, doi: 10.5194/amt-8-30692015. [Link]

Perry, G. W., C. Watson, A. D. Howarth, D. R. Themens, V. Foss, R. B. Langley, and A. W. Yau, 2019: Topside ionospheric disturbances detected using radio occultation measurements during the August 2017 solar eclipse. Geophys. Res. Lett., 46, 7069-7078, doi: 10.1029/2019GL083195. [Link]

Pradipta, R., E. Yizengaw, and P. H. Doherty, 2018: Ionospheric density irregularities, turbulence, and wave disturbances during the total solar eclipse over North America on 21 August 2017. Geophys. Res. Lett., 45, 7909-7917, doi: 10.1029/2018GL079383. [Link]

Reinisch, B. W., P. B. Dandenault, I. A. Galkin, R. Hamel, and P. G. Richards, 2018: Investigation of the electron density variation during the 21 August 2017 solar eclipse. Geophys. Res. Lett., 45, 1253-1261, doi: 10.1002/2017GL076572. [Link]

Schreiner, W., C. Rocken, S. Sokolovskiy, S. Syndergaard, and D. Hunt, 2007: Estimates of the precision of GPS radio occultations from the COSMIC/FORMOSAT-3 mission. Geophys. Res. Lett., 34, L04808, doi: 10.1029/2006GL027557. [Link]

Sun, Y.-Y., J.-Y. Liu, C.-Y. Lin, H.-F. Tsai, L. C. Chang, C.-Y. Chen, and C.-H. Chen, 2016: Ionospheric $F_{2}$ region perturbed by the 25 April 2015 Nepal earthquake. J. Geophys. Res., 121, 5778-5784, doi: 10.1002/2015JA022280. [Link]

Sun, Y.-Y., J.-Y. Liu, H.-F. Tsai, and A. Krankowski, 2017: Global ionosphere map constructed by using total electron content from ground-based GNSS receiver 
and FORMOSAT-3/COSMIC GPS occultation experiment. GPS Solut., 21, 1583-1591, doi: 10.1007/ s10291-017-0635-4. [Link]

Sun, Y.-Y., J.-Y. Liu, C. C.-H. Lin, C.-Y. Lin, M.-H. Shen, C.-H. Chen, C.-H. Chen, and M.-Y. Chou, 2018: Ionospheric bow wave induced by the moon shadow ship over the continent of United States on $21 \mathrm{Au}-$ gust 2017. Geophys. Res. Lett., 45, 538-544, doi: 10.1002/2017GL075926. [Link]

Tsai, H. F. and J. Y. Liu, 1999: Ionospheric total electron content response to solar eclipses. J. Geophys. Res.,
104, 12657-12668, doi: 10.1029/1999JA900001. [Link]

Tsai, L.-C. and J.-Y. Liu, 1997: Ionospheric observations of the solar eclipse on Oct. 24, 1995 at Chung-Li. Terr. Atmos. Ocean. Sci., 8, 221-232, doi: 10.3319/ TAO.1997.8.2.221(ASEE). [Link]

Zhang, S.-R., P. J. Erickson, L. P. Goncharenko, A. J. Coster, W. Rideout, and J. Vierinen, 2017: Ionospheric bow waves and perturbations induced by the $21 \mathrm{Au}-$ gust 2017 solar eclipse. Geophys. Res. Lett., 44, 12067 12073, doi: 10.1002/2017GL076054. [Link] 